\title{
Nonlinear Effects in Enantioselective Organometallic Catalysis*
}

\author{
H.B. Kagan \\ Institut de Chimie Moléculaire et des Matériaux d'Orsay, UMR 8182, Université Paris-Sud, 91405 Orsay - France \\ e-mail: kagan@icmo.u-psud.fr
}

*Dedicated to Yves Chauvin for his outstanding contributions to catalysis

Ce manuscrit est dédié à Yves Chauvin pour ses contributions exceptionnelles à la catalyse

\begin{abstract}
Résumé - Effets nonlinéaires dans la catalyse organométallique énantiosélective - L'historique de la catalyse organométallique énantiosélective est rappelé en introduction. Les problèmes liés à l'emploi d'auxiliaires chiraux énantioimpurs sont discutés, les effets nonlinéaires sont définis et des modèles mathématiques simples sont présentés. De nombreux exemples d'effets nonlinéaires positifs ou négatifs sont maintenant connus, certains sont mentionnés. Les effets nonlinéaires sont utiles pour aborder des mécanismes réactionnels. L'amplification asymétrique peut avoir des applications en catalyse, en permettant d'utiliser un ligand qui n'est pas énantiopur.
\end{abstract}

\begin{abstract}
Nonlinear Effects in Enantioselective Organometallic Catalysis - In the introduction are summarized the historical developments of enantioselective organometallic catalysis. Then are discussed the problems connected with the use of enantioimpure auxiliaries, the nonlinear effects are defined and some simple mathematical models are presented. Numerous examples of positive or negative nonlinear effects are presently known, some will be presented. Nonlinear effects are useful for approaching reaction mechanisms. The asymmetric amplification can have applications in catalysis, by allowing to use a ligand which is not enantiopure.
\end{abstract}

\section{INTRODUCTION}

The biological activity of many chiral compounds may depend on their absolute configuration. This is known since a long time and encouraged chemists to develop efficient routes to the preparation of a compound in the desired configuration. Resolution of a racemic mixture was the classical preparative method and is still very useful in industry. The alternated route, based on the asymmetric synthesis from an achiral starting material remained problematic for a long time. The catalytic enantioselective reactions looked the most attractive but also the most difficult to elaborate. The first nonenzymatic enantioselective catalytic reaction in 1913 was the formation of cyanohydrin (7\% ee!) from $\mathrm{HCN}$ and benzaldehyde catalyzed by quinine [1]. The development of homogeneous catalysis using organometallic complexes in mid-sixties encouraged people to prepare chiral complexes for catalysis [2]. The first and modest results were obtained in 1961 for polymerization [3], in 1966 in cyclopropanation [4] and in 1968 in hydrogenation [5, 6]. The asymmetric hydrogenation was especially promissing for applications. It used Wilkinson type precatalysts $\left(\mathrm{RhL}_{2}{ }_{2} \mathrm{Cl}\right)_{2}$ or $\left(\mathrm{RhL}_{2}{ }_{2} \mathrm{~S}\right)^{+} \mathrm{X}^{-}$where $\mathrm{L}^{*}$ was a chiral phosphine. The first generation of ligands involved monophosphines $\mathrm{L}^{*}$ where phosphorus is an asymmetric center. In 1971-1972 we introduced a new family of 


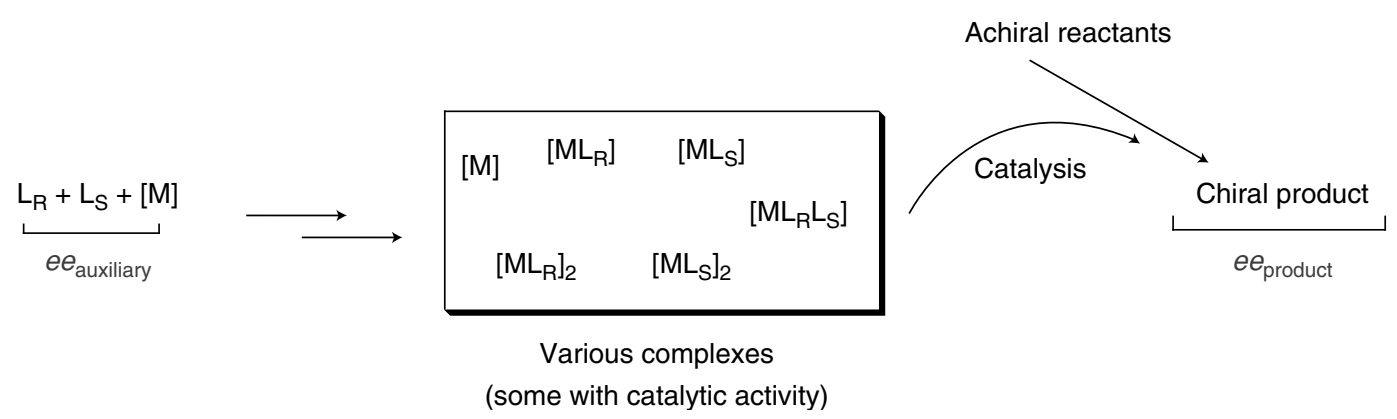

Figure 1

Formation of catalysts from a metallic precursor $(M)$ and a mixture of enantiomeric ligands $\left(L_{R}+L_{S}\right)$.

ligands, the chiral bidentate diphosphines of $\mathrm{C}_{2}$ symmetry [7, 8]. The idea was to avoid the elaboration of asymmetric phosphorus atoms and to relay the effect of remote asymmetric centers through a conformational effect given by the chelate ring [9]. Results were excellent for that time (ees up to $80 \%$ ) and obtained in Orsay in the context of a PhD work (T.P. Dang) started in 1967 and supported by the French Institute of Petroleum [10]. Many chiral $\mathrm{C}_{2}$ chelating $\mathrm{P}$ compounds were subsequently described in literature, for example dipamp in 1975 [11], chiraphos in 1977 [12], a diphosphinite with the 1,1'-binaphtyl backbone [13] and finally binap in 1980 [14]. Monophosphines $\mathrm{R}^{*} \mathrm{PPh}_{2}$, where $\mathrm{R}^{*}$ is a chiral group, were less successful [15]. It was only in 2000 that it was discovered that some phosphorus ligands such as $(\mathrm{RO})_{2} \mathrm{PNR}_{2}$ or $(\mathrm{RO})_{2} \mathrm{POR}^{\prime}$ are excellent ligands for asymmetric hydrogenation $[16,17]$.

\section{ENANTIOIMPURE AUXILIARIES IN ASYMMETRIC CATALYSIS}

Chiral catalysts can be well-defined molecular species and are prepared from some chiral auxiliaries, this is schematized in Figure 1 when the auxiliary is not enantiopure $\left(e e_{\text {auxiliary }}<100 \%\right)$.

If the chiral catalysts are not enantiomerically pure and are considered as acting independently one from each other, then it is easy to calculate the enantiomeric excess of the resulting reaction product [18]. The enantiopure $(+)$-catalyst will provide a product with a given enantiomeric excess $\left(e e_{\max }\right)$, the enantiomeric $(-)$-catalyst will generate a product of opposite configuration with the same enantiomeric excess $\left(-e e_{\max }\right)$. The racemic catalyst gives of course a racemic product. When the catalyst has an intermediate enantiomeric excess $e e_{\text {auxiliary }}$ the resultant product has an enantiomeric excess intermediate between 0 and $e e_{\max }$. Calculations give the simple Equation 1, where $e e_{\text {product }}$ is proportional to $e e_{\text {auxiliary }}$. In the equation ees values are taken between 0 and 1 .

$$
e e_{\text {product }}=e e_{\max } e e_{\text {auxiliary }}
$$

This equation can be rigorously established. For that purpose the only assumption required is that mixtures of various amounts of the enantiomeric auxiliaries will provide, in the same relative amounts, two asymmetric syntheses with identical rate constants, but giving products of opposite absolute configurations. The general validity of Equation 1 has been questioned by Izumi and Tai [19]. In 1986, we demonstrated with Prof. C. Agami for the first time that deviations from Equation 1 may indeed occur in asymmetric catalysis [20]. These deviations were named "nonlinear effects" (NLE) to illustrate that the curves $e e_{\text {product }}=\mathrm{f}\left(e e_{\text {auxiliary }}\right)$ are no longer the straight lines defined by Equation 1. In this plot $e e_{\max }$ state for the $e e$ obtained with an enantiopure ligand. A positive nonlinear effect $[(+)-\mathrm{NLE}]$ characterizes situations such as that of curve A in Figure 2, where the product is of a higher $e e$ than the value given by the straight line B. A negative nonlinear effect [(-)-NLE] corresponds to curves of type $\mathrm{C}$, where the products are of lower ee than expected. The terms asymmetric amplification [21, 22] and asymmetric depletion [18] are currently used as synonyms of (+)- and (-)-NLE, respectively.

In our 1986 paper, we presented one case of asymmetric amplification (Sharpless epoxidation of geraniol) and one case of asymmetric depletion (sulfide oxidation in presence of a chiral titanium complex). The proline-catalyzed intramolecular aldol reaction (Hajos-Parrish reaction) gave rise to a weak (-)-NLE which has been recently reinvestigated [23, 24]. Since 1986, many examples of NLE have been discovered in a wide variety of reactions mostly for organometallic catalysts. Some reviews have been published [25-30]. Asymmetric amplification has been specifically reviewed in references [18, 29]. 


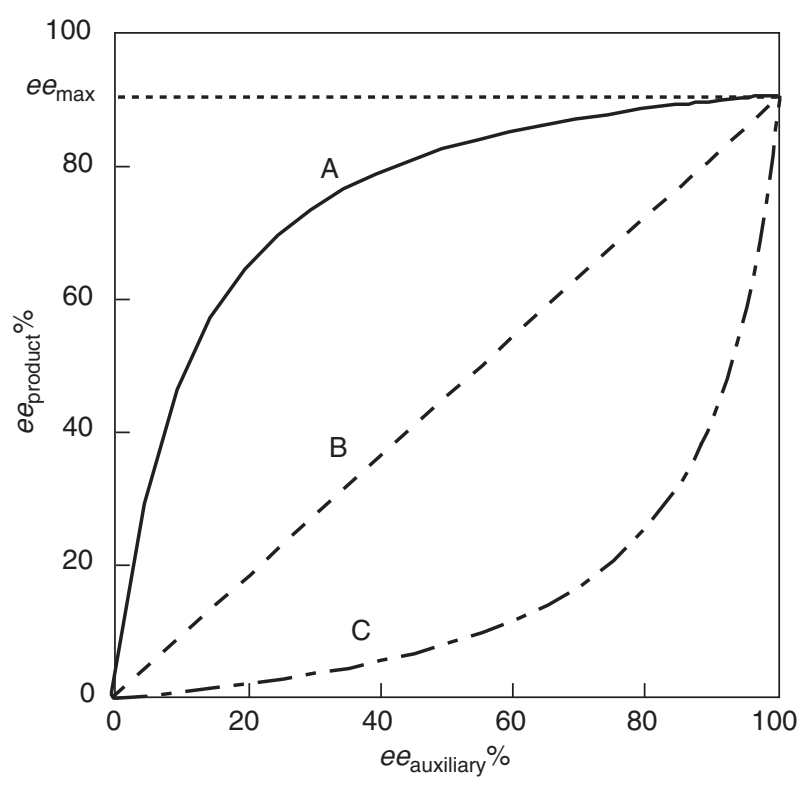

Figure 2

The three main plots relating the ee of the chiral auxiliary to the ee of product in enantioselective catalysis.

\section{SOME CONDITIONS FOR OBSERVING A NONLINEAR EFFECT}

When two enantiomeric catalysts are mixed in various amounts, the prediction of the enantiomeric purity of the products is easy, provided that the mixing does not introduce additional interactions between the enantiomorphic systems. In this ideal behavior, simple additivity rules will give rise to Equation 1 (linearity). A deviation from ideal behavior must generate diastereomeric species that are not present in the homochiral systems with, as a possible consequence, a deviation from linearity. In the kinetic framework, the non-ideal behavior will introduce new reaction paths and may change the kinetics from those defined with the enantiopure catalysts.

Let us clarify these points by considering a metal complex bearing two ligands (L) symbolized as $\mathrm{ML}_{2}$. The corresponding enantiopure catalysts with chiral ligands $\left(\mathrm{L}_{\mathrm{R}}\right.$ or $\left.\mathrm{L}_{\mathrm{S}}\right)$ may be of the type $M L_{R} L_{R}$ or $M L_{S} L_{S}$. If the ligand has some enantiomeric excess $\left(e e_{\text {auxiliary }}\right)$, a heterochiral complex $\mathrm{ML}_{\mathrm{R}} \mathrm{L}_{\mathrm{S}}$ assumed of meso structure for simplicity, may be created in addition to $\mathrm{ML}_{\mathrm{R}} \mathrm{L}_{\mathrm{R}}$ and $\mathrm{ML}_{\mathrm{S}} \mathrm{L}_{\mathrm{S}}$. The meso-complex is a diastereomer of the two homochiral complexes, it will generate a racemic product and its catalytic activity may be very different of that exerted by the homochiral complexes. It will introduce a perturbation which cannot be predicted from the simple knowledge of the behavior of the homochiral catalysts. In such cases a deviation from
Equation 1 can occur, giving a nonlinear effect. The perturbation arises from the "heterochiral marriage" of the two enantiomeric auxiliaries, either inside (vide infra) or outside the catalytic cycle.

There are innumerable examples of kinetic schemes which may introduce non-linearity. They share in common some additional pathways or equilibria by respect to the reactions carried out with the enantiopure catalysts, building up new species.

If the catalyst is modified by the product (autoinduction processes [31, 32]), additional complications will occur which may give rise to nonlinearity. This aspect, as well as asymmetric autocatalytic reactions $[18,29]$, will not be considered here.

\section{SOME SIMPLE MODELS}

We have described two fundamental and simple models of nonlinear effects, as seen below.

\subsection{Kinetic Model}

We proposed a model where the unusual behavior of the chiral auxiliary reflects the formation of catalytic species involving several chiral ligands [20, 22]. If $\mathrm{L}_{\mathrm{R}}$ and $\mathrm{L}_{\mathrm{S}}$ are the two enantiomeric ligands of a metal (M) bearing $n$ ligands (L), one may simply represent the complexes as $\mathrm{ML}_{n}$. $\mathrm{ML}_{2}$ complexes, or the dimeric species (ML) ${ }_{2}$, are the simplest ways of assembling two chiral ligands within a complex. This model, however, does not take into account other co-ligands or additional possibilities of stereoisomerism, and it assumes that there is no free chiral ligand. A minimum of three stereoisomeric complexes are generated, namely two homochiral complexes $\left(\mathrm{ML}_{\mathrm{R}} \mathrm{L}_{\mathrm{R}}\right.$ and $\left.\mathrm{ML}_{\mathrm{S}} \mathrm{L}_{\mathrm{S}}\right)$ and one heterochiral (meso) complex $\left(\mathrm{ML}_{\mathrm{R}} \mathrm{L}_{\mathrm{S}}\right)$. The chiral products $\mathrm{P}_{\mathrm{R}}$ and $\mathrm{P}_{\mathrm{S}}$ are obtained from these three catalysts (Fig. 3). The heterochiral catalyst will give a racemic mixture of products whereas the two homochiral catalysts will generate products of opposite absolute configuration with enantiomeric excess $e e_{\text {product }}=e e_{\max }$. The overall enantiomeric excess of the product will depend on the relative amounts of the three catalysts present $(x, y$ and $z)$ and on their relative reactivities $\left(k_{\text {homo }}=\right.$ $\left.k_{R R}=k_{S S}, k_{\text {hetero }}=k_{R S}\right)$.

A simple calculation has been performed $[20,22]$ to express $e e_{\text {product }}$ as a function of the relative amount $\beta$ of heterochiral catalyst present and of its relative reactivity $g$, as defined in Equation 2.

$$
\beta=z /(x+y) \text { and } g=k_{R S} / k_{R R}
$$

In Figure 3 an equilibrium is assumed between the three complexes. $K$ is defined as the equilibrium constant of interconversion between the three complexes and is related to the 


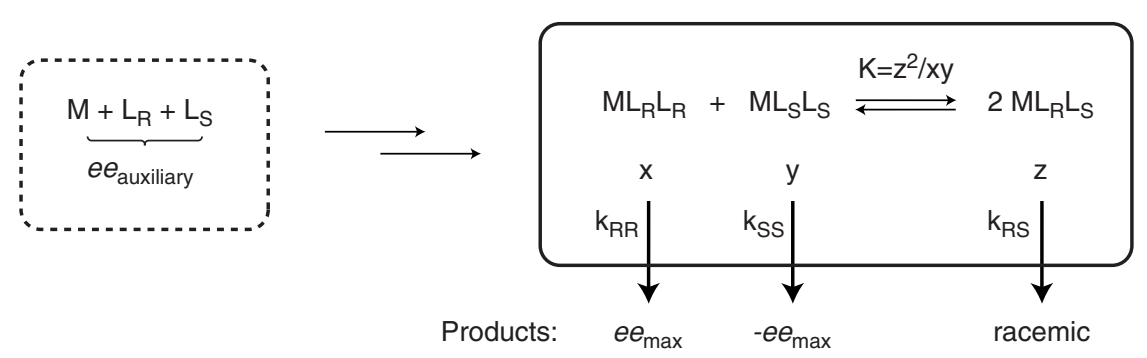

Figure 3

The $\mathrm{ML}_{2}$ model [20, 22].

relative amount $\beta$ of heterochiral catalyst. The kinetic calculations give formula (3) where ee's are defined as being $<1$.

$$
e e_{\text {product }}=e e_{\max } e e_{\text {auxiliary }}(1+\beta) /(1+g \beta)
$$

If $\beta=0$ (no heterochiral catalyst) or $g=1$ (same reactivity of hetero and homochiral catalysts) then $(1+\beta) /(1+g \beta)=1$, giving linearity. When $g<1$, it comes $(1+\beta) /(1+g \beta)>1$, providing an asymmetric amplification. Thus the necessary condition for asymmetric amplification in the above model is for the heterochiral catalyst to be less reactive than the homochiral catalyst. If the heterochiral catalyst is more reac-

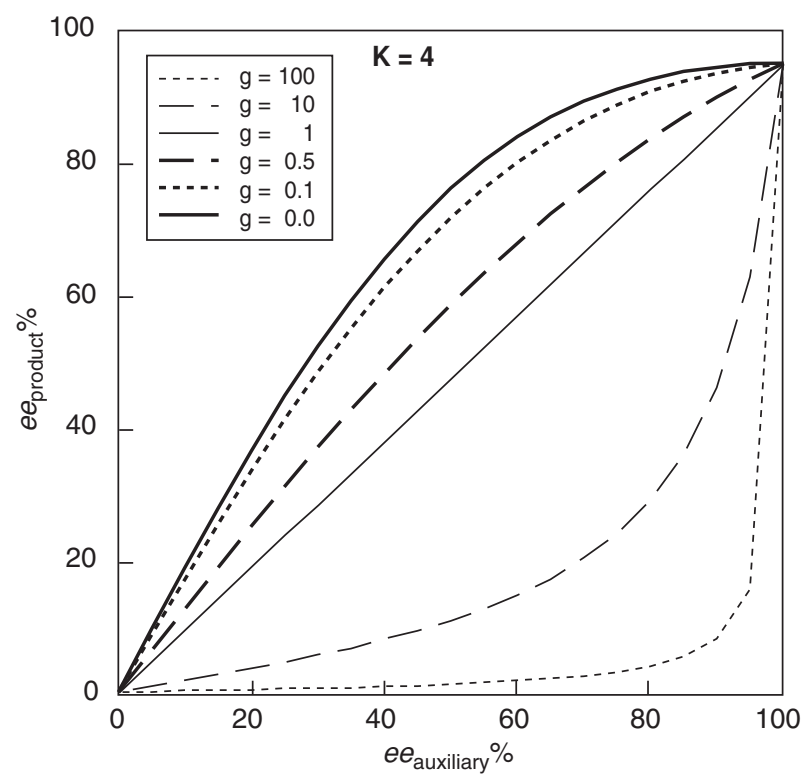

Figure 4

Plots computed from equation 3 whith a statistical distribution of ligands in the complexes $(K=4)$ [22]. tive then $(1+\beta) /(1+g \beta)<1$ and hence a negative nonlinear effect is observed. The size of the asymmetric amplification is regulated by the value of $(1+\beta) /(1+g \beta)$ which increases as $K$ does. The more heterochiral catalyst (of the lowest possible reactivity) there is, the higher will be $e e_{\text {product }}$. This is well illustrated by computed curves in Figure 4 . The variation of $e e_{\text {product }}$ with $e e_{\text {auxiliary }}$ is represented for various values of $g$ (the relative reactivity of the meso complex) with $K=4$ (corresponding to a statistical distribution of ligands in the complexes). The $\mathrm{ML}_{2}$ model has been extended to complexes with more than two ligands, a generalized $\mathrm{ML}_{n}$ model has been discussed, especially for $n=3$ or 4 [22].

\subsection{Reservoir Effect}

The above asymmetric amplification is a consequence of an in situ increase in the ee of the active catalyst, since racemic ligand is trapped in the unreactive or weakly reactive meso catalyst. In the reservoir effect a similar phenomenon occurs outside the catalytic cycle. Let us assume that part of the initial chiral ligand characterized by $e e_{\text {auxiliary }}$, is diverted into a set of catalytically inactive complexes (Fig. 5). A common scenario is a pre-equilibrium between monomers and dimers (inactive) with an equilibrium constant $K$ which fixes the size of the reservoir as a function of $e e_{\text {auxiliary. }}$ One case is indicated in Figure 5. Strong amplifications at low $e e_{\text {auxiliary }}$ may be achieved using suitable values of $K$.

\section{REACTION RATES IN NONLINEAR EFFECTS}

New diastereomeric species may be generated if the chiral auxiliaries are enantioimpure. As a direct consequence, this modifies the overall reaction rate (in comparison to that of the enantiopure system), as pointed out by Blackmond [33]. This is easily understandable by looking at the models of Figure 3. In the $\mathrm{ML}_{2}$ model, an asymmetric amplification means a low reactivity and a high amount of the heterochiral 


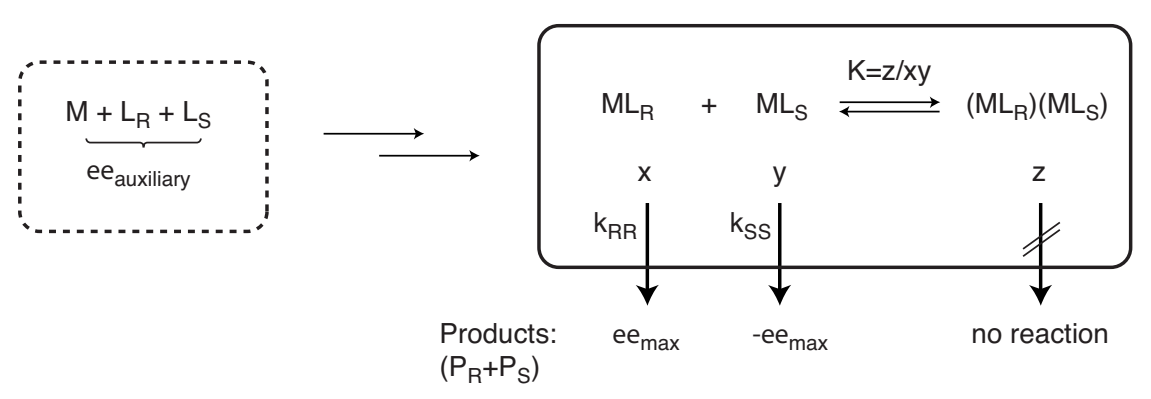

Figure 5

The reservoir model where monomeric complexes are catalytically active and a meso-dimer is inactive.

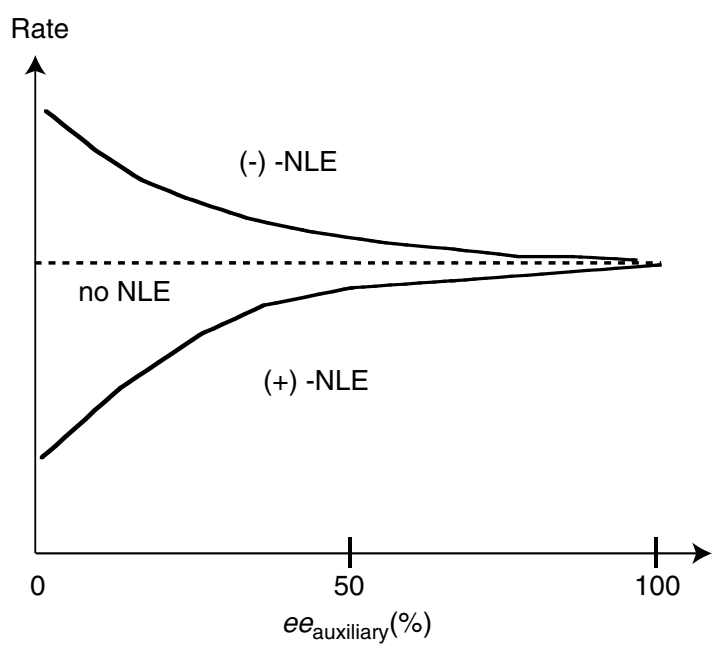

Figure 6

The three main cases of relationships between reaction rates and ee of the ligand in enantioselective catalysis.

catalyst, hence a lowering of the global reactivity in comparison to a mixture of homochiral catalysts. The bonus given by the (+)-NLE has to be paid by a deficit, the decrease in the catalytic activity. The same conclusion is reached for the ML model with homochiral dimerization (Fig. 5). The decrease of the amount of ligand available for the monomeric catalysts consequently lowers the quantity of catalytic species in respect to the reference systems with enantiopure ligands. The general relationships between the rates and the enantiomeric excesses of the chiral auxiliary are represented in Figure 6.

\section{SOME EXAMPLES OF NONLINEAR EFFECTS}

Most of the nonlinear effects have been described for organometallic catalysts, but some organocatalysts may give rise to nonlinear effects as recently discovered. Organocatalysis will be not discussed here.

Enantioselective organozinc additions on aldehydes is possible in presence of a catalytic amount of a chiral aminoalcohol. The catalytic species is the zinc alcoholate which is prone to dimerize in solution. Noyori et al discovered and studied a spectacular (+)-NLE in the addition of $\mathrm{Et}_{2} \mathrm{Zn}$ on benzaldehyde (Fig. 7) [34, 35]. They carefully studied all the facets of the reaction and proposed a reservoir mechanism. The key factor for the asymmetric amplification is the formation of a stable heterodimer $\mathrm{Zn}$ alcoholate which amplifies the enantiomeric excess of the acting monomeric species.

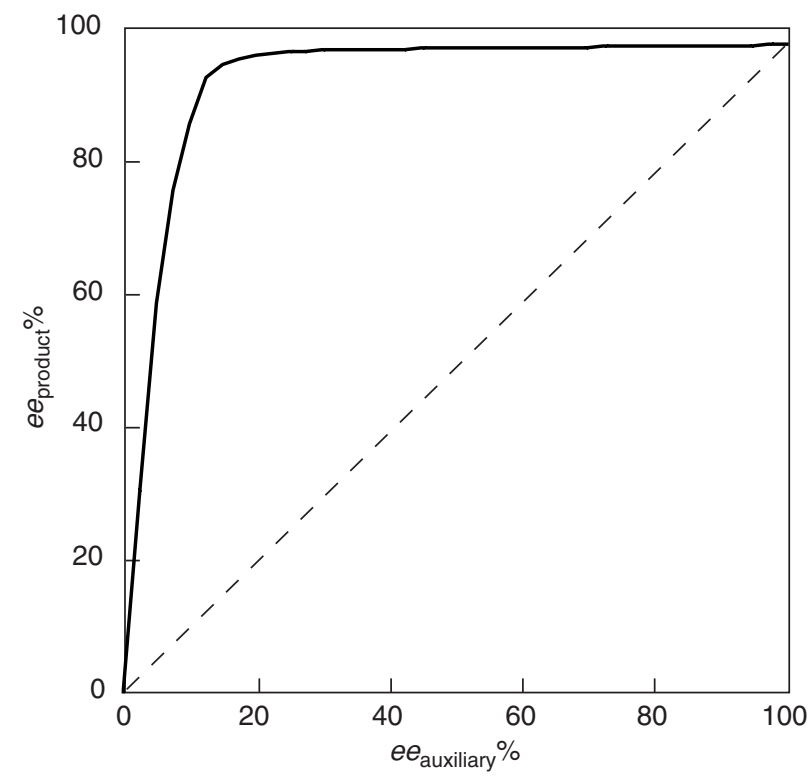

Figure 7

Asymmetric amplification in the reaction of $\mathrm{Et}_{2} \mathrm{Zn}$ on benzaldehyde catalyzed by DAIB, a $\beta$-aminoalcohol [34] (Curve redrawn from Ref. [34]). 
Many classes of reactions gave rise to nonlinear effects. The organometallic catalysts are often based on $\mathrm{Ti}, \mathrm{Zn}, \mathrm{Cu}$, $\mathrm{Ni}, \mathrm{Cr}, \mathrm{Ln}, \mathrm{Ru}$ or Rh. For example Diels-Alder reactions have been catalyzed by complexes prepared from $\mathrm{Ti}(\mathrm{O} i-\mathrm{Pr})_{4} /$ binol or taddol [36], [37] or bis-oxazoline/Ni complexes [38], the 1,4-addition of phenylboronic acid on enones have been catalyzed by a $\mathrm{Rh}(\mathrm{OH})$ binap complex [39]. The aza-Michael reaction on chalcone catalyzed by rare-earth-Li-binaphtoxides complexes gave a high (+)-NLE [40]. The glyoxylateene reactions catalyzed by a Ti/binol complex is one early example of a strong asymmetric amplification [41].

Hydrogenation of $\beta$-ketoesters catalyzed by $\mathrm{RuBr}_{2}$ binap [42] or hydrogenation of dimethyl itaconate catalyzed by $\mathrm{Rh} / 2 \mathrm{~L}^{*}\left(\mathrm{~L}^{*}=\right.$ chiral monophosphite) [43] provided an excellent asymmetric amplification. We have investigated the enantioselective oxidation of sulfides into sulfoxides by hydroperoxides. It was discovered that $(+)$ or (-)-NLE could be generated according to the experimental conditions, the catalyst being generated from $\mathrm{Ti}(\mathrm{O} i-\mathrm{Pr})_{4} /(+)-$ diethyl tartrate and various additives [44]. The ring opening of meso-epoxides by $\mathrm{N}_{3} \mathrm{SiMe}_{3}$ was catalyzed by a $\mathrm{CrN}_{3} /$ chiral salen complex, providing an important (+)NLE [45]. This short list shows the large diversity of reactions and catalysts (Lewis acid type or transition-metal complex) able to display a nonlinear effect when the ligand is not enantiopure.

\section{MECHANISTIC APPLICATIONS}

In asymmetric catalysis it is important to optimize the enantioselectivity in the transformation of a given substrate, by a fine tuning of the structure of the catalyst and of the experimental conditions. For that purpose some knowledge about the reaction mechanism may be very useful. In this context the study of nonlinear effects is emerging as a simple and additional mechanistic tool.

The presence of (+)- or (-)-NLE is a good argument for some complexity in the kinetic scheme, with the formation of species containing several ligands giving rise to diastereomers. Often, the aggregation of a complex may be detected by a (+)-NLE coming from heterodimers or heterooligomers of low reactivity. Reactions which are second-order in catalyst may also give rise to NLE (as in asymmetric meso-epoxide opening) [45].

A nonlinear effect coupled with some kinetic data give a significant insight into the mechanistic scheme of a catalytic system. For this purpose several rate laws have been elaborated, based on alternative mechanisms. Then, the simulation of the curves $e e_{\text {product }}=\mathrm{f}\left(e e_{\text {auxiliary }}\right)$ and rates $=\mathrm{f}\left(e e_{\text {auxiliary }}\right)$ may be compared with the experimental data, allowing one to retain the hypothesis that gives the better fit $[39,43,45]$.

In catalytic reactions where no NLE is observed, it is difficult to draw any conclusions. The linearity may reflect the monomeric character of all the ML complexes. It may also be the result of an aggregation of ML complexes or formation of $\mathrm{ML}_{2}$ complexes, with parameters providing linearity. For example, the $\mathrm{ML}_{2}$ system (Fig. 2) displays linearity if the heterochiral complexes have the same reactivity as the homochiral complexes $(g=1)$ or are not formed $(\beta=0)$. Similar conclusions have been drawn for dimers (ML) derived from ML monomers.

\section{CONCLUSION}

Asymmetric amplification is one of the most interesting aspect of nonlinear effects. It is essentially generated by the 'anihilation' of two ligands of opposite configuration in unreactive species (inside or outside the catalytic cycle) [25]. A direct consequence of the reservoir effect or of the lower reactivity of heterochiral species is the enhancement of the enantiomeric excess of the reactive species. This beneficial effect, however, is balanced by a decrease in the reaction rate since a smaller amount of active catalyst is available for reaction. The lowering of reaction rate will be especially strong for low $e e_{\text {auxiliary }}$ due to the greater formation of heterochiral species. This effect has been often experimentally observed and quantitatively discussed in connection with $\mathrm{ML}_{\mathrm{n}}$ models [33]. In the $\mathrm{ML}_{2}$ model (Fig. 3 and Equation 3), for example, it is possible to calculate the values of $x, y$ and $z$ which define the relative amounts of the three catalysts (as a function of $K$ and $e e_{\text {auxiliary }}$ ). The overall rate of formation of products may then be obtained as a function of $K$ and $e e_{\text {auxiliary }}$. The comparison of calculated and experimental rates should provide a simple tool for the support of a mechanistic model [33].

The mechanisms for the in situ enhancement of the catalyst ee bear a similarity to the 'Horeau-Langenbeck duplication' which can be used for the enhancement of $e e$ of an enantioimpure compound $[46,47]$. In this approach a mixture of enantiomeric monomers $R$ and $S$ are coupled with an achiral bifunctional linker to give a mixture of dimers $R-R, S-S$ and $R-S$. The $R-S$ dimer (diastereomeric to the homochiral combinations $R-R$ and $S-S$ ) is separated and the remaining enantiomeric mixture of dimers cleaved to generate a mixture of monomers $R$ and $S$ of enhanced $e e$ (even if the coupling reaction gave a statistical distribution of products).

The $\mathrm{ML}_{n}$ model ( $n=3$ or 4 ) has been used to predict an unusual nonlinear effect where the enantiomeric excess of the product increases when the ee of chiral auxiliary decreases [22]. Such an effect (hyper NLE) is presented in Figure 8 (curve A) and remains to be discovered. For example a $\mathrm{ML}_{3}$ system may provide the homochiral complexes $\left(M L_{R} L_{R} L_{R}\right.$ and $\left.\mathrm{ML}_{S} \mathrm{~L}_{S} \mathrm{~L}_{S}\right)$ and the heterochiral complexes $\left(\mathrm{ML}_{R} \mathrm{~L}_{R} \mathrm{~L}_{S}\right.$ and $\mathrm{ML}_{S} \mathrm{~L}_{\mathrm{R}} \mathrm{L}_{\mathrm{R}}$ ). Let assume that the heterochiral complexes are more stereoselective and much more active catalysts than the homochiral complexes. 


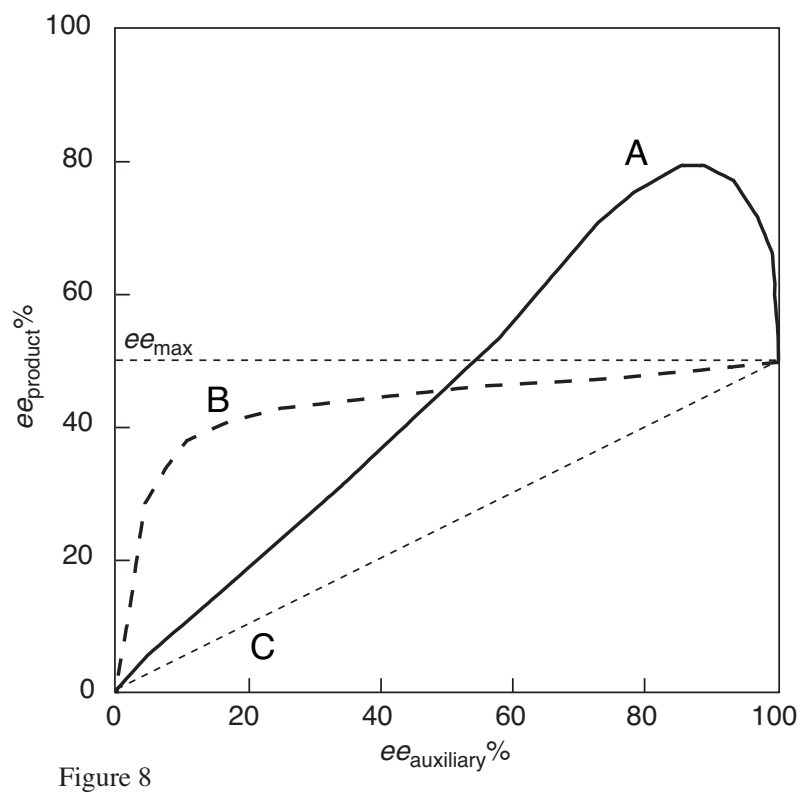

Prediction of an unusual (+)-NLE (curve A) instead of the classical (+)-NLE (curve B).

In Figure 8 the enantiopure ligand gives a product of $50 \%$ $e e$. As soon as the ee of the ligand is inferior to $100 \%$ there is the possibility to generate the heterochiral complexes which will dominate the reaction. Of course at some point the beneficial effect of decreasing $e e_{\text {auxiliary }}$ will disappear, since at low values of $e e_{\text {auxiliary }}$ the heterochiral complexes will be abundant but of low ee. The curves B (usual (+)-NLE) and C (linearity) will be replaced by curve A. In reference [22] are given some numerical calculations and a computed curve of hyper NLE.

The $\mathrm{ML}_{\mathrm{n}}$ model also allowed to generate multi-shape curves or curves giving simultaneously (+)-NLE and (-)NLE for some domains of $e e_{\text {auxiliary }}$. Some distorted curves have been experimentally observed.

In conclusion the plot $e e_{\text {product }}=\mathrm{f}\left(e e_{\text {auxiliary }}\right)$ is a simple tool in asymmetric catalysis to analyze a system. However it has to be combined to kinetics studies to draw firm conclusions on the mechanism of the reaction. The presence of a positive nonlinear effect may avoid to prepare enantiopure ligands. Asymmetric amplification is also useful in enantioselective autocatalysis, [29, 30] and hence feed the discussions on the processes occuring in prebiotic times leading to homochirality of living systems [48].

\section{ACKNOWLEDGEMENT}

I warmly thank all my coworkers and colleagues whose names appear in our papers quoted below. I acknowledge CNRS, University Paris-Sud and French Institute of Petroleum for a financial support.

\section{REFERENCES}

1 Bredig, G. and Fiske, P.S. (1913) Asymmetric synthesis caused by catalyts. Biochem. Z., 46, 7-23.

2 For history of asymmetric catalysis see: Kagan, H.B. (1999) Historical perspective, in Comprehensive Asymmetric Catalysis, Jacobsen, E.N., Pfaltz, A. and Yamamoto, H. (eds.), SpringerVerlag, Berlin, Vol. 1, pp. 9-30.

3 Natta, G., Farina, M., Peraldo, M. and Bressan, G. (1961) Asymmetric synthesis of optically active di-isotactic polymers from cyclic monomers. Makromol. Chem., 43, 68-75.

4 Nozaki, H., Moriuti, S., Takaya, H. and Noyori, R. (1966) Asymmetric induction in carbenoid reactions by means of a dissymmetric copper chelate. Tetrahedron Lett., 22, 5239-5244.

5 Knowles, W.S. and Sabacky, M.J. (1968) Asymmetric hydrogenation employing a soluble, optically active, rhodium complex. Chem. Commun., 1445-1446.

6 Horner, L, Siegel, H. and Büthe, H. (1968) Asymmetric catalytic hydrogenation with an optically active phosphinerhodium complex in homogeneous solution. Angew. Chem. Int. Edit. Engl., 7, 942.

7 Dang, T.P. and Kagan, H.B. (1971) The asymmetric synthesis of hydratropic acid and amino acids by homogeneous catalytic hydrogenation. Chem. Commun., 481.

8 Kagan, H.B. and Dang, T.P. (1972) Asymmetric catalytic reduction with transition metal complexes. -I. A catalytic system of rhodium(I) with (-)-2,3-O-isopropylidene-2,3-dihydroxy 1,4(diphenylphosphino)butane, a new chiral diphosphine. J. Am. Chem. Soc., 94, 6429-6433.

9 Kagan, H.B. (1975) Asymmetric catalysis by chiral rhodium complexes in hydrogenation and hydrosilylation reactions. Pure Appl. Chem., 43, 401-421.

10 Dang, T.P. and Kagan, H.B. (1970) Bidentate coordinates, their manufacture and application, Patent IFP, France, Dec. 10, 1970, US, Dec. 7, 1971, Ser. No. 205, 744.

11 Knowles, W.S., Sabacky, M., Vineyard, B.D. and Weinkauff, D.J. (1975) Asymmetric hydrogenation with a complex of rhodium and a chiral biphosphine. J. Am. Chem. Soc., 97, 29672968.

12 Fryzuk, M.D. and Bosnich, B. (1977) Asymmetric synthesis. Production of optically active amino acids by catalytic hydrogenation. J. Am. Chem. Soc., 99, 6262-6267.

13 Grubbs, R.H. and DeVries, R.A. (1977) Asymmetric hydrogenation by an atropoisomeric diphosphinite rhodium complex. Tetrahedron Lett., 18, 1879-1880.

14 Miyashita, A., Yasuda, A., Takaya, H., Toriumi, K., Ito, T., Souji, T. and Noyori, R. (1980) Synthesis of 2,2'bis(diphenylphosphino)-1,1'-bis-naphthyl (BINAP), an atropoisomeric chiral bis(triaryl)phosphine and its use in the rhodium(I)-catalyzed asymmetric hydrogenation of $\beta$ aminoacrylic acids. J. Am. Chem. Soc., 102, 7932-7934.

15 Lagasse, F. and Kagan, H.B. (2000) Chiral monophosphines as ligands for asymmetric catalysis. Chem. Pharm. Bull., 48, 315-324.

16 Reetz, M. and Mehler, G. (2000) Highly enantioselective Rh-catalyzed hydrogenation reactions based on chiral monophosphite ligands. Angew. Chem. Int. Edit., 39, 3889-3890.

17 Van der Berg, M., Minnaard, A.J., Schudde, E.P., van Esch J., de Vries, A.H.M., deVries, J.G. and Feringa, B.L. (2000) Highly enantioselective rhodium-catalyzed hydrogenation with monodentate ligands. J. Am. Chem. Soc., 122, 11539-11540.

18 Kagan, H.B. and Fenwick, D.R. (1999) Asymmetric amplification. Topics Stereochem., Denmark, S. Ed., 22, 257-296. 
19 Izumi, Y. and Tai, A. (1977) Stereo-Differentiating Reactions, Academic Press, New York, pp. 242-245.

20 Puchot, C., Samuel, O., Dunach, E., Zhao, S., Agami, C. and Kagan, H.B. (1986) Nonlinear effects in asymmetric synthesis. Examples in asymmetric oxidation and aldolization reactions. $J$. Am. Chem. Soc., 108, 2353-2357.

21 Oguni, N., Matsuda, Y. and Kaneko, T. (1988) Asymmetric amplifying phenomena in enantioselective addition of diethylzinc to benzadehyde. J. Am. Chem. Soc., 110, 7877-7878.

22 Guillaneux, D., Zhao, S.H., Samuel, O., Rainford, D. and Kagan, H.B. (1994) Nonlinear effects in asymmetric catalysis. J. Am. Chem.Soc., 116, 9430-9439.

23 Hoang, L., Bahmanayar, S., Houk, K.N. and List, B. (2003) Kinetic and stereochemical evidence for the involvement of only one proline molecule in the transition state of praline catalyzed intra- and intermolecular aldol reactions. J. Am. Chem. Soc., 125, 16-17.

24 Mathew, S.P., Iwamura, H. and Blackmond, D.G. (2006) Amplification of enantiomeric excess in a proline-mediated reaction. Angew. Chem. Int. Edit., 43, 3317-3321.

25 Girard, C. and Kagan, H.B. (1998) Nonlinear effects in asymmetric synthesis and stereoselective reactions: ten years of investigation. Angew. Chem. Int. Edit. Engl., 37, 2922-2959.

26 Kagan, H.B. (2001) Nonlinear effects in asymmetric catalysis: a personal account. Synlett, 888-900.

27 Kagan, H.B. (2001) Practical consequences of nonlinear effects in asymmetric synthesis. Adv. Synth. Catal., 343, 227-233.

28 Avalos, M., Babiano, R., Cintas, P., Jiménez, J.L. and Palacios, J.C. (1997) Nonlinear stereochemical effects in asymmetric reactions. Tetrahedron-Asymmetr., 8, 2997- 3017.

29 Soai, K., Shibata, T. and Sato, I. (2000) Enantioselective automultiplication of chiral molecules by asymmetric catalysis. Accounts Chem. Res., 33, 382-390.

30 Kagan, H.B. and Luukas, T.O. (1999) Nonlinear effects and autocatalysis, in Comprehensive Asymmetric Catalysis, Jacobsen, E.N., Pfaltz, A and Yamamoto, H. (eds.), SpringerVerlag, Berlin, Vol. 1, pp. 101-118.

31 Alberts, AH. and Wynberg, H. (1989) The role of the product in asymmetric $\mathrm{C}-\mathrm{C}$ bond formation: stoichiometric and catalytic enatioselective autoinduction. J. Am. Chem. Soc., 111, 7265-7266.

32 (a) Bolm, C., Bienewald, F. and Seger, A. (1996) Asymmetric autocatalysis with amplification of chirality. Angew. Chem. Int . Edit. Engl., 35, 2922-2959 and references quoted therein. (b) Costa, A.M, Garcia, C., Caroll, P.J. and Walsh, P.J. (2005) Dramatic catalyst evolution in the asymmetric addition of diethylzinc to benzaldehyde. Tetrahedron, 61, 6442-6446 and references quoted therein.

33 Blackmond, D.G. (1997) Mathematical models of nonlinear effects in asymmetric catalysis: new insights based on the role of reaction rate. J. Am. Chem. Soc., 119, 12934-12939.

34 Kitamura, M., Okada, S., Suga, S. and Noyori, R. (1989) Enantioselective addition of dialkylzincs to aldehydes promoted by chiral amino alcohols. Mechanism and nonlinear effect. $J$. Am. Chem. Soc., 111, 4028-4036.

35 Noyori, R. and Kitamura, L. (1991) Enantioselective addition of organometallic reagents to carbonyl compounds: chirality transfer, multiplication, and amplification. Angew. Chem. Int. Edit., 30, 49-69.
36 Mikami, K., Motoyama, Y. and Terada, M. (1994) Asymmetric catalysis of Diels-Alder cycloadditions by an MS-free binaphthol-titanium complex: dramatic effect of MS, linear vs. positive nonlinear relationship, and synthetic applications. J. Am. Chem. Soc., 116, 2912-2820.

37 Iwasawa, N., Hayashi, Y., Sakurai, H. and Narasaka, K. (1989) Characterization of the chiral titanium reagent prepared from the tartrate-derived chiral diol and titanium dichloride diisopropoxide. Chem. Lett., 1581-1584.

38 Kanemasa, S., Oderaotoshi, Y., Sakakguchi, S., Yamamoto, H., Tanaka, J., Wada, E. and Curran, D.P. (1998) Transition-metal aqua complexes of 4,6-dibenzofurandiyl-2,2'-bis(4-phenyloxazoline). Effective catalysis in Diels-Alder reactions showing excellent enantioselectivity, extreme chiral amplification and high tolerance to water, alcohols, amines and acids. J. Am. Chem. Soc., 120, 3074-3088.

39 Kina, A., Iwamura, H. and Hayashi, T. (2006) A kinetic study on $\mathrm{Rh} /$ Binap-catalyzed 1,4-addition of phenylboronic acid to enones: negative nonlinear effect caused by predominant homochiral dimer contribution. J. Am. Chem. Soc., 128, 39043905.

40 Yamagiwa N., Qin H., Matsunaga S. and Shibasaki M. (2005) Lewis acid-Lewis acid heterobimetallic cooperative catalysis: mechanistic studies and application in enantioselective azaMichael reaction. J. Am. Chem. Soc., 127, 13419-13427.

41 Terada, M., Mikami, K. and Nakai, T. (1990) Asymmetric catalysis for carbonyl-ene reaction. Synlett, 255-264.

42 Girard, C., Genet, J.-P. and Buillard, M. (1999) Non-linear effects in ruthenium-catalyzed asymmetric hydrogenation with atropisomeric diphosphanes. Eur. J. Org. Chem., 11, 2937-2942.

43 Reetz, M.T., Meiswenkel, A., Mehler, G., Angermund, K., Graf, M., Thiel, W., Mynott, R. and Blackmond, D.G. (2005) Why are BINOL-based monophosphites such efficient ligands in Rh-catalyzed asymmetric olefin hydrogenation? J. Am. Chem. Soc., 127, 10305-10313.

44 Brunel, J.-M., Luukas, T.O. and Kagan, H.B. (1998) Nonlinear effects as 'indicators' in the tuning of asymmetric catalysts. Tetrahedron-Asymmetr., 9, 1941-1946.

45 Hansen, K.B, Leighton, J.L. and Jacobsen, E.N. (1996) On the mechanism of asymmetric nucleophilic ring-opening of epoxides catalyzed by (Salen)Cr ${ }^{\mathrm{III}}$ complexes. J. Am. Chem. Soc., 118, 10924-10925.

46 Vigneron, J.-P., Dhaenens, M. and Horeau, A. (1973) Nouvelle méthode pour porter au maximum la pureté optique d'un produit partiellement dédoublé sans l'aide d'aucune substance chirale. Tetrahedron, 29, 1055-1059.

47 (a) Langenbeck, W. and Triem, G. (1936) Theories of the origin and maintenance of optical activity in nature. Z. Phys. Chem. A, 177, 401-409. (b) Heller, D., Drexler, H.-J., Fischer, C., Buschmann, H., Baumann, W. and Heller, B. (2000) How long have nonlinear effects been known in the field of catalists. Angew. Chem. Int. Edit., 39, 495-499.

48 Buschmann, H., Thede, R. and Heller, D. (2000) New developments in the origin of the homochirality of biologically relevant molecules. Angew. Chem. Int. Edit., 39, 4033-4036.

Final manuscript received in March 2007 or distributed for profit or commercial advantage and that copies bear this notice and the full citation on the first page. Copyrights for components of this work owned by others than IFP must be honored. Abstracting with credit is permitted. To copy otherwise, to republish, to post on servers, or to redistribute to lists, requires prior specific permission and/or a fee: Request permission from Documentation, Institut français du pétrole, fax. +33147527078 , or revueogst@ifp.fr. 